\title{
Matthew-Wood syndrome
}

INSERM

\section{Source}

INSERM. (1999). Orphanet: an online rare disease and orphan drug data base. Matthew-

Wood syndrome. ORPHA:2470

Matthew-Wood syndrome is a rare clinical entity including as main characteristics

anophthalmia or severe microphthalmia, and pulmonary hypoplasia or aplasia. 